\title{
A comparative study of locking plate by minimally invasive percutaneous plate osteosynthesis versus closed interlocking intramedullary nail in extra-articular distal tibia fractures
}

\author{
Jojin Jose Chitten*, R. Balasubramaniam
}

Department of Orthopaedics, SVMC and RC, Puducherry, India

Received: 21 March 2021

Revised: 26 March 2021

Accepted: 30 March 2021

*Correspondence:

Dr. Jojin Jose Chitten,

E-mail: jojinjosec@gmail.com

Copyright: (C) the author(s), publisher and licensee Medip Academy. This is an open-access article distributed under the terms of the Creative Commons Attribution Non-Commercial License, which permits unrestricted non-commercial use, distribution, and reproduction in any medium, provided the original work is properly cited.

\begin{abstract}
Background: To compare functional outcome between minimally invasive percutaneous plate osteosynthesis (MIPO) and intramedullary interlocking nail (IMIL) in the distal one-third extra-articular tibia fracture.

Methods: We retrospectively analysed 32 patients with closed distal tibia extra-articular fractures who underwent IMIL nail and locking plate MIPO technique in 16 patients each. All patients were followed for at least one year with assessment of clinico-radiological union and functional outcome scoring.

Results: There was comparable functional outcomes, time to union and surgical time both in IMIL nail and MIPO fixation of closed distal extra-articular tibia fractures with similar complication rate.

Conclusions: Our study suggests that both IMIL nail and MIPO fixation could be used for closed distal extra-articular tibia fractures as per surgeon's preference. However, due to small sample size in our study, we cannot draw any definitive conclusions from our preliminary results but consider them as valuable basis for future studies.
\end{abstract}

Keywords: Intramedullary interlocking nail, MIPO, Distal tibia fracture, Extra-articular

\section{INTRODUCTION}

Distal tibia fractures have the second highest incidence of all tibia fractures after the middle third of tibia. ${ }^{1}$ The distal tibia is defined according to Müller and AO/association for the study of internal fixation (ASIF) definitions as a fracture primarily located within the "Müller square," which is a square with sides of a length defined by the widest portion of the tibial plafond. The distal tibia fractures are considered challenging to treat due to of its proximity to the ankle joint, its subcutaneous nature and poor blood supply. Thus, complications like non-union, delayed union and infections are very common along with difficulty in maintenance of reduction. ${ }^{2}$ IMIL nailing and MIPO are advocated options of treatment for these fractures. However, there is no concrete evidence regarding which is a better treatment option. While MIPO is associated with wound problems, plate prominence, IMIL nailing is technical difficult in insertion and has the risk of mal-union. ${ }^{3,4}$ The objective of the current study is to compare both these modalities of management in closed distal third extra- articular tibia fractures in terms of radiological and functional outcomes.

\section{METHODS}

After getting clearance from institutional review board, we performed a retrospective comparative study on thirty-two patients who had a unilateral, closed extra-articular distal tibial fracture who underwent either minimally invasive 
plate osteosynthesis (MIPO) with anatomical distal tibia locking plate or closed IMIL nailing between October 2018 to March 2020 in a tertiary hospital. For the purpose of sample size calculation, time to union was taken as the primary outcome. Assuming a pooled standard deviation of 2.49 weeks for time to union in both the groups ${ }^{5}$, the study would require a sample size of 11 in each group to achieve a power of $80 \%$ and a level of significance of $5 \%$ (two sides) for detecting a difference to heal of 3 weeks. A final sample of 15 in each group was taken to compensate for drop outs.

The criteria for inclusion in the study were, age of at least eighteen years, closed OTA type 43 A fractures. Patients with associated compartment syndrome or neurovascular injury, open fractures, pathological fractures, local infection, those with inadequate follow up were excluded from the study.

Selection of implant for particular fracture was entirely based on operating surgeon's discretion and no other factors were taken into consideration. The fractures were classified according to the orthopaedic trauma association (OTA) classification. The associated fibular fracture was fixed either with plate or intra-medullary K-wire, only if it was at or below the level of tibial fractures. Initial management consisted of splinting with long leg plaster slab. Sixteen patients were treated with IMIL nailing and 16 patients were fixed with stainless distal tibia locking plates. Fibula fracture, if in distal third was fixed first with either $3.5 \mathrm{~mm}$ one-third plate or an elastic nail and its fixation is independent of tibial method of fixation. Intravenous antibiotics consisting of ceftriaxone sulbactam and gentamicin were administered preoperatively and for 3 days post-operatively for both the groups. Non-weight bearing was recommended for 2 weeks post-operatively for both groups. Partial weight wearing was initiated from third week after suture removal and gradual transition to full weight bearing at the end of six weeks post operatively.

Patients were evaluated with radiographs in both anteroposterior and lateral views of ankle joint and distal tibia pre-operatively, immediate post-operatively and at 6weeks, three months, six months and nine months. Distal tibia is defined as the area within two Muller squares of the ankle joint, in which the proximal and the distal segments of long bones are defined by a square whose sides have the same length as the widest part of the epiphysis. Mal-union was defined as 5 degree of angular deformity or translation/shortening of $10 \mathrm{~mm}$. Fracture union was defined clinically as no pain or tenderness at the fracture site and radiologically as healing of at least three of four cortices on bi-planar plain radiographs. Delayed union was defined as lack of any healing on plain radiographs within 3 months. Non-union was defined as lack of any healing on plain radiographs within 6 months. Superficial infection was confined to dermal and subcutaneous tissue whereas deep infection was defined as those below the deep investing muscular fascia. At the end of follow-up (after 1 year), clinical outcome was evaluated according to the American orthopaedic foot and ankle score as excellent (90-100), good (75-89), fair (50-74) and poor $(<50)$.

\section{Statistical analysis}

Statistical analysis was done using Graph pad prism 9.0.0 (California, USA). Continuous data was summarised as median and interquartile range (IQR) and categorical data, as percentages. Shapiro-Wilk test was used to test for normality of continuous data. Median values for baseline and post-operative data were compared using the Wilcoxon-matched pairs signs rank test.

\section{RESULTS}

Patients who had nailing were significantly younger, with median age of 26.5 years (19.0-38.0) while those who underwent MIPO had a median age of 46 years (31.7-54), which was statistically significant (Table 1). Associated fibula fractures were present in a smaller proportion of the patients who had MIPO $(56.25 \%)$ than those who had nailing $(93.75 \%)$ and the difference was statistically significant $(\mathrm{p}=0.0373)$ (Table 1$)$.

Table 1: Baseline characteristics of patients undergoing MIPO/nailing.

\begin{tabular}{|c|c|c|c|}
\hline Variables & MIPO & Nail & P value \\
\hline Age (year) & $\begin{array}{l}46.0 \\
(31.7- \\
54.0)\end{array}$ & $\begin{array}{l}26.5 \\
(19.0- \\
38.0)\end{array}$ & $0.0011 *$ \\
\hline \multicolumn{4}{|l|}{ Gender } \\
\hline Male & $12(75.0)$ & $14(87.5)$ & \multirow{2}{*}{0.6539} \\
\hline Female & $4(25.0)$ & $2(12.5)$ & \\
\hline \multicolumn{3}{|l|}{ Side } & \multirow{3}{*}{0.4578} \\
\hline Right & $12(75.0)$ & $9(56.2)$ & \\
\hline Left & $4(25.0)$ & $7(43.8)$ & \\
\hline \multicolumn{3}{|l|}{ MOI } & \multirow{3}{*}{0.5996} \\
\hline RTA & $13(81.2)$ & $15(93.7)$ & \\
\hline Fall & $3(18.7)$ & $1(6.3)$ & \\
\hline \multicolumn{3}{|c|}{ AO classification } & \multirow{4}{*}{0.3114} \\
\hline $43 \mathrm{~A} 1$ & $2(12.5)$ & $2(12.5)$ & \\
\hline $43 \mathrm{~A} 2$ & $6(37.5)$ & $10(62.5)$ & \\
\hline $43 \mathrm{~A} 3$ & $8(50.0)$ & $4(25.0)$ & \\
\hline \multicolumn{3}{|c|}{ Associated fibula\# } & \multirow{3}{*}{$0.0373 *$} \\
\hline Yes & $9(56.2)$ & $15(93.7)$ & \\
\hline No & $7(43.8)$ & $1(6.3)$ & \\
\hline
\end{tabular}

$* \mathrm{p}<0.05$. Continuous variables are summarized as median (IQR) and categorical variables as percentages.

Continuous variables are summarized as median (IQR) and categorical variables as percentages. Mann-Whitney U test was used to compare continuous variables and Chisquare/Fisher's exact test, for categorical variables.

The median difference in time taken for union was 2.5 weeks (95\% CI: 0.0-4.0). But the difference was not statistically significant $(\mathrm{p}=0.1968)$ (Table 2$)$. 
There were $12.5 \%$ complications in each of the groups with two mal-unions in the nailing group and one implant irritation and one superficial infection in the MIPO group.

Table 2: Radiological and functional outcome.

\begin{tabular}{|c|c|c|c|c|}
\hline Variables & MIPO & $\begin{array}{l}\text { IMIL } \\
\text { nail }\end{array}$ & $\begin{array}{l}P \\
\text { value }\end{array}$ & $\begin{array}{l}\text { Median } \\
\text { difference } \\
\text { (95\% CI) }\end{array}$ \\
\hline $\begin{array}{l}\text { Duration } \\
\text { of } \\
\text { surgery } \\
\text { (hours) }\end{array}$ & $\begin{array}{l}2.0 \\
(2.0- \\
2.5)\end{array}$ & $\begin{array}{l}2.3 \\
(2.0- \\
3.4)\end{array}$ & 0.4545 & $\begin{array}{l}0.25 \\
(-0.25 \text { to } \\
1.0)\end{array}$ \\
\hline $\begin{array}{l}\text { Time to } \\
\text { union } \\
\text { (weeks) }\end{array}$ & $\begin{array}{l}24 \\
(24.0- \\
28.0)\end{array}$ & $\begin{array}{l}27 \\
(24.0- \\
28.0)\end{array}$ & 0.1968 & $\begin{array}{l}2.5 \\
(0.0-4.0)\end{array}$ \\
\hline \multicolumn{3}{|c|}{ AOFAS score } & \multirow{4}{*}{0.9092} & \multirow{4}{*}{----- } \\
\hline Fair & $2(12.5)$ & $2(12.5)$ & & \\
\hline Good & $3(18.7)$ & $4(25.0)$ & & \\
\hline Excellent & $\begin{array}{l}11 \\
(68.8)\end{array}$ & $\begin{array}{l}10 \\
(62.5)\end{array}$ & & \\
\hline
\end{tabular}

\section{DISCUSSION}

Our study included thirty-two distal tibia fractures treated with either MIPO or an intra-medullary interlocking nail. In this study majority were males; $75 \%$ of males in MIPO group and $87.5 \%$ of the nailing group (Table 1). The same trend is observed in similar studies. Guo et al had $59 \%$ male and $41 \%$ female in nailing group and same percentages in in plating group. Predominant involvement of male sex in both the groups can be explained, as males are more frequently exposed to outdoor activities and hence more involved in road side accidents. We had $87.5 \%$ of the total patients who sustained injury secondary to road traffic accidents, which explains the higher proportion of males. $^{6}$

In this study the functional outcome in terms of AOFAS score as well as time taken for radiological in both the groups were statistically similar indicating comparable outcomes with both nail as well as MIPO technique. Our study is concurrent with the study by Guo et al who used the American orthopaedic foot and ankle surgery (AOFAS) scoring system as well as study by Li et al who used Olerud-Molander ankle score to evaluate the functional results. Both these studies showed no statistically significant difference between the functional outcome of either intra-medullary interlocking or MIPO group. Thus, suggesting that closed intramedullary interlocking nailing and a MIPO can be used safely and effectively to treat distal metaphyseal fractures of the tibia. However, the retrospective study by $\mathrm{Li}$ et al including 46 patients found that the mean operating time was $76.1 \pm 16.6$ minutes for the interlocking nail group was significantly shorter when compared with in the MIPO group (90.4 \pm 20.3 minutes), whereas in our study the duration of both the techniques were comparable. ${ }^{7}$
The current study had a comparable radiological fracture union time of median of 24 weeks in the MIPO group and 27 weeks in the nailing group, with no statistical significance (Table 2). Similarly, Kasper et al study showed mean time of radiographic union of 19 weeks with plate group and 21 weeks with nail group. ${ }^{8}$ In addition, Guo et al. study 17.7 weeks for mean radiographic union with nailing and 17.6 weeks for plate group. ${ }^{6}$ Vallier et al shown his study that mean union time is 19 weeks for both plate and nail group. ${ }^{9}$ In contrast, study by Tzeng et al. showed mean union times of 22.6 weeks in nailing group and 27.8 weeks in the plating group, which was statistically significant proving that nailing had a faster healing. ${ }^{9}$ It has been found that preservation of soft tissue envelope and blood supply surrounding the fractures by using indirect reduction techniques would promote fracture healing regardless of type of fixation, which is the case in both these methods of biological fixation.

In the current study, we observed complication rate of $12.5 \%$ each in both the nailing and the MIPO groups. While the nailing group had two mal-unions, the plating group had one implant irritation and one superficial infection which was settled with regular dressings and antibiotics. In case of Lau et al retrospective study of the clinical outcome using metaphyseal locking plate by the MIPO technique in a much higher sample size of 48 patients with distal tibia fractures, they found $17 \%$ of infection rate; four patients were treated by antibiotics, but one patient required debridement and other three incision and drainage..$^{11}$ But recent studies have demonstrated less soft tissue problems and reasonably lessens the risk of infection. ${ }^{12}$ At same, time distal tibia fractures can be difficult to control with intramedullary device leading to malunion rates of $5-58 \%$, which is concurrent with our study of $12.5 \%$ of malunion. ${ }^{13}$

This study is limited by its low sample size and also the patients who had nailing were significantly younger, compared to those had MIPO.

\section{CONCLUSION}

Our study suggests that both plate osteosynthesis by minimally invasive technique and intramedullary interlocking nailing are equally effective methods of stabilisation for distal tibia fracture when considering the union rates and final functional outcome. However, due to small sample size in our study, we cannot draw any definitive conclusions from our preliminary results but consider them as valuable basis for future studies.

Funding: No funding sources Conflict of interest: None declared

Ethical approval: The study was approved by the institutional ethics committee 


\section{REFERENCES}

1. Court-Brown CM, McBirnie J. The epidemiology of tibial fractures. J Bone Joint Surg Br. 1995;77(3):417e21.

2. Blick SS, Brumback RJ, Lakatos R, Poka A, Burgess AR. Early prophylactic bone grafting of high-energy tibial fractures. Clin Orthop Relat Res. 1989;(240):21e41.

3. Andalib A, Sheikhbahaei E, Andalib Z, Tahririan MA. Effectiveness of minimally invasive plate osteosynthesis (MIPO) on comminuted tibial or femoral fractures. Arch Bone Jt Surg. 2017;5:290-5.

4. Fu B. Locked META intramedullary nailing fixation for tibial fractures via a suprapatellar approach. Indian J Orthop. 2016;50:283-9.

5. Daolagupu AK, Mudgal A, Agarwala V, Dutta KK. A comparative study of intramedullary interlocking nailing and minimally invasive plate osteosynthesis in extra articular distal tibial fractures. Indian J Orthop. 2017;51(3):292-8.

6. Guo JJ, Tang N, Yang HL, Tang TS. A prospective, randomized trial comparing closed inramedullary nailing with percutaneous plating in the treatment of distal metaphyseal fractures of the tibia. J Bone Joint Surg Br. 2010;92(7):984-8.

7. Lei L, Xin T, Fuxing P, Guanglin W, Yue F, Hui Z et al. Comparison of low, multidirectional locked nailing and plating in the treatment of distal tibial metadiaphyseal fractures. Int Orthop. 2012;36:1457e62.
8. Janssen KW, Biert J, Van Kampen A. Treatment of distal tibial fractures: plate versus nail A retrospective outcome analysis of matched pairs of patients. Int Orthop. 2007;31:709-14.

9. Vallier HA, Le TT, Bedi A. Radiographic and clinical comparisons of distal tibia shaft fractures (4 to $11 \mathrm{~cm}$ proximal to the plafond): plating versus intramedullary nailing. J Orthop Trauma. 2008;22(5):307-11.

10. Vallier HA, Le T. Radiographic and clinical comparison of distal tibia shaft fractures plating vs. intramedullary nailing. $\mathrm{J}$ Orthop Trauma. 2008;22(5):307-11.

11. Lau TW, Leung F, Chan CF, Chow SP. Minimally invasive plate osteosynthesis in the treatment of proximal humeral fracture. Int Orthop. 2007;31:657-64.

12. Collinge C, Kuper M, Protzman R. Minimally invasive plating of high energy Metaphyseal distal tibia fractures. J Orthop Trauma. 2007;21(6):355-61.

13. Resch H, Pechlaner S, Benedetto KP. Long term results after conservative and surgical treatment of fractures of the distal end of tibia. Aktuelle Traumatol. 1986;16:117-23.

Cite this article as: Chitten JJ, Balasubramaniam R. A comparative study of locking plate by minimally invasive percutaneous plate osteosynthesis versus closed interlocking intramedullary nail in extra-articular distal tibia fractures. Int J Res Orthop 2021;7:557-60. 